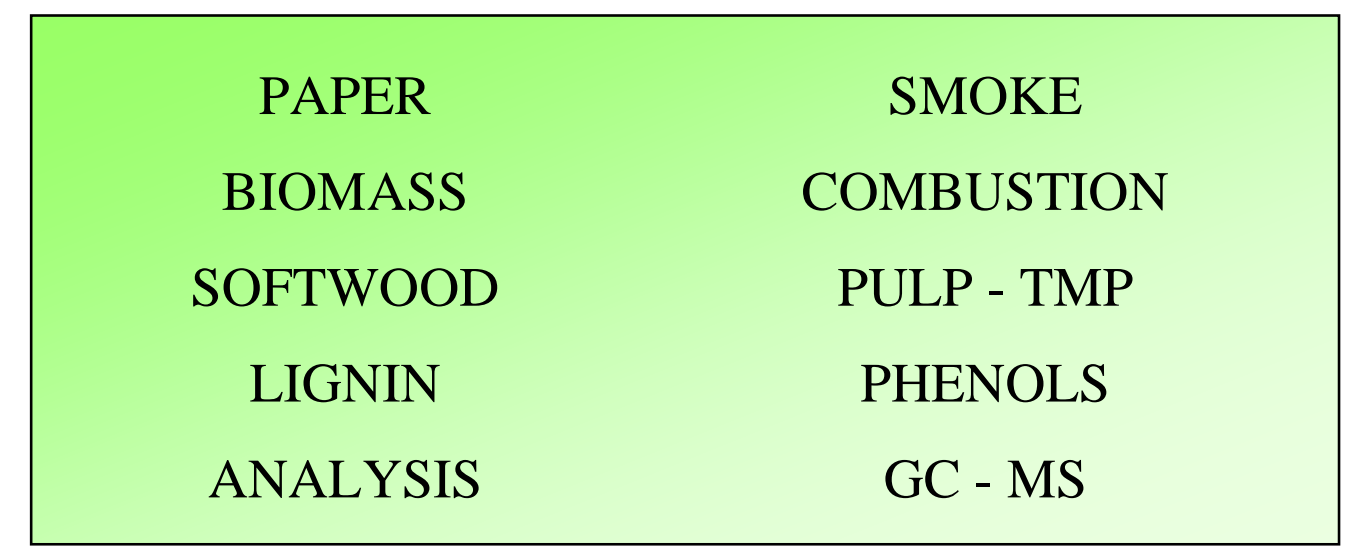

Open access revised manuscript version of Nordic Pulp \& Paper 15 (2000) 98-100 Link to publisher

\title{
Coniferyl alcohol from newsprint burning
}

Jennica Kjällstrand and Göran Petersson

Related studies of methoxyphenols released from lignin were made for wood burning and forest biomass burning 


\section{Coniferyl alcohol from newsprint burning}

Jennica Kjällstrand and Göran Petersson, Chalmers University of Technology, Göteborg, Sweden

Keywords: Combustion, Pyrolysis, Smoke, Lignin, Paper, TMP, Methoxyphenols, Coniferaldehyde, Vanillin, Gas chromatography.

SUMMARY: Coniferyl alcohol constitutes almost half of the amount of methoxyphenols in smoke from choked burning of newsprint produced from thermomechanical pulp. The results indicate that coniferyl alcohol is a key component not only in biosynthesis but also in thermal decomposition of lignin. The trans isomer was formed in $5-10$ times larger amounts than the cis isomer. Coniferyl alcohol and the oxidised analogue coniferaldehyde were also shown to be the most prominent methoxyphenols in chimney smoke from stove burning of newsprint.

The methoxyphenols were determined by gas chromatography and mass spectrometry both after direct smoke injection and after adsorbent sampling combined with thermal desorption. Coniferyl alcohol is more reactive and less volatile than commonly reported methoxyphenols in smoke from biomass burning. Its assessment therefore depends on adequate methods for sampling and analysis.

\footnotetext{
ADDRESS OF THE AUTHORS: Department of Chemical Environmental Science, Chalmers University of Technology, SE-412 96 Göteborg, Sweden. Correspondence regarding this article should be addressed to G. Petersson.
}

Coniferyl alcohol, 3-(4-hydroxy-3-methoxyphenyl)-2-propen-1-ol, is the basic unit from which conifer lignin is biosynthesised (Brunow et al. 1999). It is also a major incorporated unit in the lignin polymers of other plants, together with its 4-hydroxy-3,5-dimethoxyphenyl analogue, sinapyl alcohol.

The cis and trans isomers of coniferyl and sinapyl alcohol were reported in a previous qualitative study of a wide range of lignin-related methoxyphenols from burning of wood (Kjällstrand et al. 1998). They have also been determined as products from micro-scale heating at $620{ }^{\circ} \mathrm{C}$ of wood, different pulps and lignin (Kleen, Gellerstedt 1991). The qualitative formation of coniferyl alcohol from pyrolysis of biomass materials has been 
observed in many studies. This includes early reports of a wide range of phenolic compounds from wood pyrolysis (Faix et al. 1990; Pouwels et al. 1987).

Recent studies of smoke from burning of native forest biomass materials (Kjällstrand et al. 2000) demonstrated coniferyl alcohol to be a minor component relative to other 2methoxyphenols. The contrasting high proportions of coniferyl alcohol from newsprint should be of interest with respect to both lignin degradation and environmental considerations, and were therefore subjected to this study.

\section{Materials and Methods}

The following data apply to the burning experiments, to the methods for direct sampling and adsorbent sampling, and to the analytical methods.

\section{Newsprint burning}

Newsprint

: Produced from $80 \%$ thermomechanical pulp (TMP) from spruce (Picea abies) and $20 \%$ pulp from recycled paper

Newspaper : Göteborgs-Posten, the leading daily newspaper in the Göteborg region

Fuel

: A few margin strips ( $1 \mathrm{~g}$ ) without print for pot burning; several pages for stove burning

Laboratory burning : In a ceramic pot (1.5 l) placed in a fume cupboard; flame cholking with a clay pot kept upside-down

Tiled stove $\quad$ : In a residential house; smoke outlet at about $6 \mathrm{~m}$ height, through long stove and chimney channels

\section{Sampling and injection}

Direct sampling : Through bottom hole in clay pot, with gas-tight syringe (500 $\mu$ l, SGE), preflushed with smoke

Sample injection : Splitless, $10-30$ seconds after sampling, $220^{\circ} \mathrm{C}$

Adsorbent

: Tenax TA, 60-80 mesh, $0.1 \mathrm{~g}$, kept inside injector glass liner, initially conditioned at $250^{\circ} \mathrm{C}$

Adsorbent samples : Pot samples of 1-3 ml withdrawn using a $10 \mathrm{ml}$ gas-tight syringe; chimney samples of $10 \mathrm{ml}$ taken with an air pump during 5 minutes

Desorption

: In injector, with restriction in liner fitted to analytical column, at $100^{\circ} \mathrm{C}$ raised $60^{\circ} \mathrm{C} \mathrm{min}^{-1}$ to $220^{\circ} \mathrm{C}$ 


\section{Analyses}

Gas chromatograph : Varian 3800 (MS-linked)

Carrier gas : Helium, $1.1 \mathrm{ml} \mathrm{min}^{-1}$

Column $\quad: 30 \mathrm{~m} \times 0.25 \mathrm{~mm}$ i.d., FSOT (fused silica open tubular)

Stationary phase $\quad$ : Cyanopropylphenylsilicone, Rtx 1701

Oven temperature : Increased $5^{\circ} \mathrm{C} \min ^{-1}$ from $50^{\circ} \mathrm{C}$ to $200^{\circ} \mathrm{C}$ and then kept isothermal

Mass spectrometer : Varian Saturn 2000 , ion trap $\left(150^{\circ} \mathrm{C}\right)$, electron impact (EI, $\left.70 \mathrm{eV}\right)$

Mass spectra : Mass range $m / z$ 35-400, 1 spectrum $\mathrm{s}^{-1}$ recorded and data-stored

Response : Qualitative response set equal for all methoxyphenols; determined for vanillin by injecting a reference solution and for guaiacol by gas injection after evaporation of a reference sample into a glass container (50 1).

\section{Results and Discussion}

\section{Proportions of coniferyl alcohol}

The highest proportions of coniferyl alcohol were obtained from flaming burning followed by rapid choking. In Table 1, results from four such experiments are given. Uniform methoxyphenol proportions were obtained for the two very different sampling methods. All observed methoxyphenols had the 4-hydroxy-3-methoxyphenyl (guaiacyl, Gu) structure characteristic of conifer lignin. This is to be expected because Scandinavian thermomechanical pulp for newsprint is produced from Norway spruce (Picea abies). The gas chromatographic separation of the components is illustrated in Figure 1 for the experiment corresponding to the first column in the table. Gas chromatographic and mass spectrometric data were given for a wide range of methoxyphenols in a previous study (Kjällstrand et al. 1998).

The two isomeric coniferyl alcohols $\left(\mathrm{GuCH}=\mathrm{CHCH}_{2} \mathrm{OH}\right)$ constituted almost half of the amount of methoxyphenols from choked burning. The amount of the trans isomer was $5-10$ times larger than that of the cis isomer. Similar isomer ratios were observed for $\mathrm{GuCH}=\mathrm{CHCH}_{3}$ and are ascribed to steric hindrance for the cis isomers. The high proportion of coniferyl alcohol demonstrates that the chemical structure of the lignin permits a favourable release of this basic monomer. Observed proportions of coniferyl alcohol are much lower for unprocessed coniferous biomass materials (Kjällstrand et al. 2000). Apparently, the physically and chemically modified structure of thermomechanical pulp and newsprint 
Table 1. Composition (\%) of methoxyphenols in smoke from newsprint burning (Gu $=4$-hydroxy-3-methoxyphenyl)

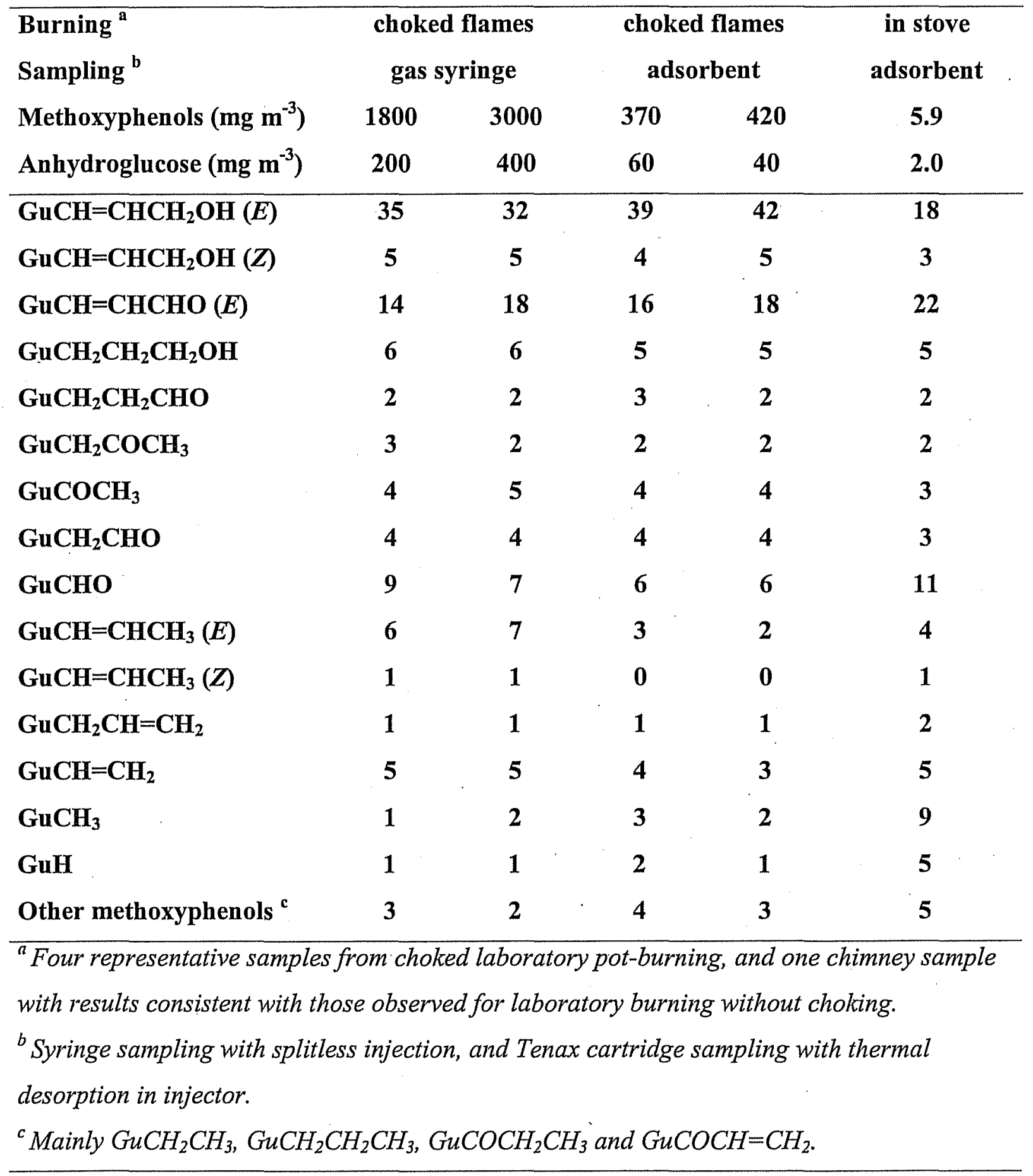




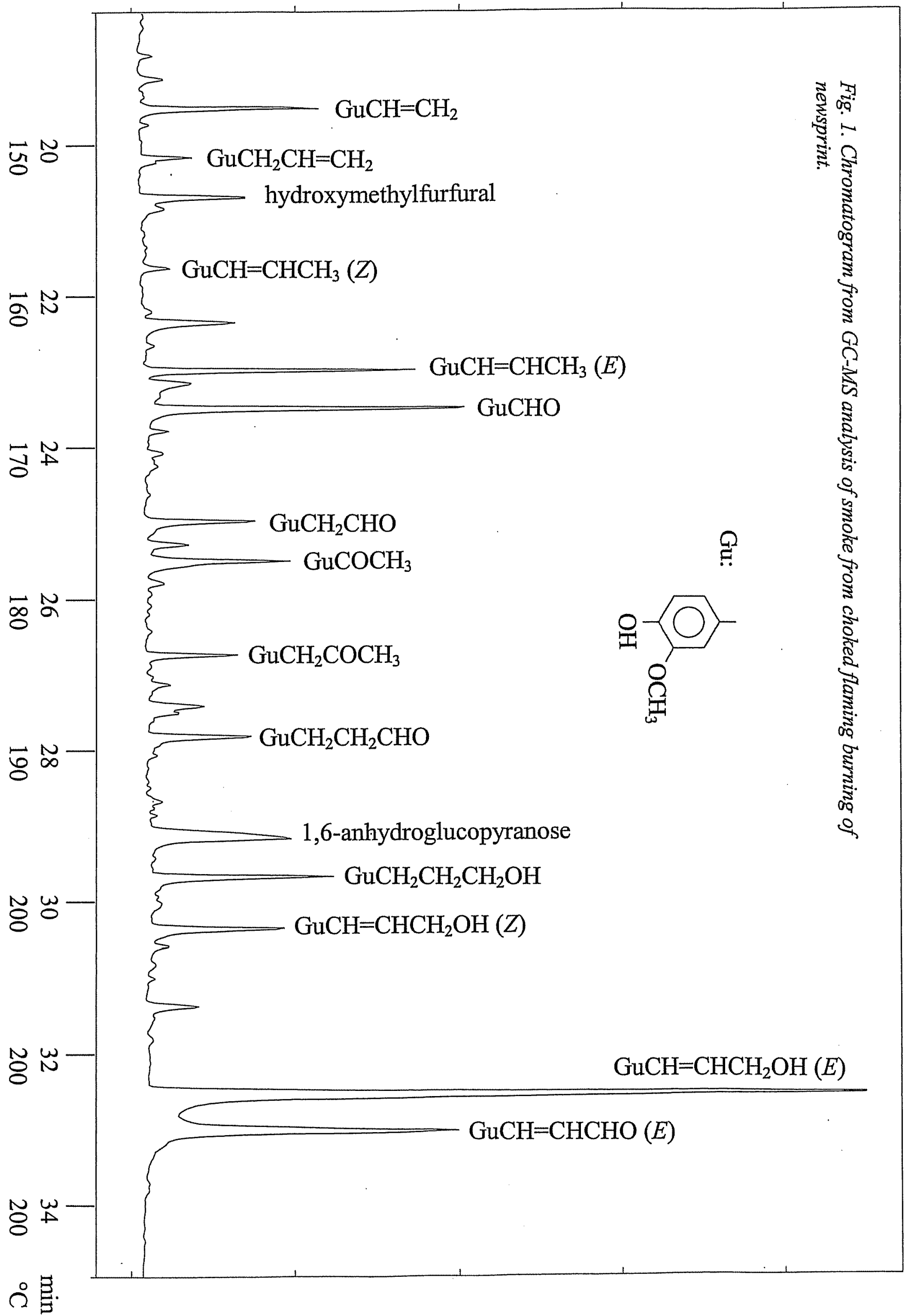


facilitates release of coniferyl alcohol. This conclusion is supported by observed high proportions of coniferyl alcohol from controlled micro-scale heating at $620^{\circ} \mathrm{C}$ of mechanical pulps from spruce (Kleen, Gellerstedt 1991).

\section{Analytical aspects}

The high proportion of coniferyl alcohol is surprising regarding its high chemical reactivity. Oxidations to coniferaldehyde or vanillin are two obvious reaction paths. Coniferaldehyde, $\mathrm{GuCH}=\mathrm{CHCHO}$, was the second most prominent methoxyphenol, with predominance for the trans isomer. Partial oxidation, increasing the ratio between aldehyde and alcohol, was indicated for high initial injector desorption temperature. A leading shape of the aldehyde peak in the chromatogram also indicates that oxidation may occur in the chromatographic system. There is little doubt, however, that coniferaldehyde constitutes $10-20 \%$ of the methoxyphenols in the smoke. The results refer to marginal white newsprint, but no great differences were obtained for newsprint with text and pictures.

Coniferyl alcohol is also more polar and less volatile compared to the other methoxyphenols. This is reflected in more tailing of the chromatographic peak, although the stationary phase is quite polar. Condensation losses in the gas syringe were decreased by flushing the syringe with the hot smoke several times before sampling. Injection was also made without delay after sampling.

Use of Tenax cartridges permits storing of samples. Decomposition by reactions on the adsorbent during and after sampling is a potential source of error, but the observed proportions of coniferyl alcohol were rather higher than for syringe sampling. For low concentrations in smoke from open burning and in chimney smoke, adsorbent sampling is an option whereas syringe sampling is not.

It is concluded that quantitative determination is a more difficult task for coniferyl alcohol than for other reported 2-methoxyphenols in smoke. The analytical parameters and the analytical procedures were therefore optimised to minimise losses of coniferyl alcohol. This was done for sequences of newsprint burning experiments under varied analytical conditions. The uniform quantitative results in Table 1 for the widely different gas sampling and adsorbent sampling methods indicate quantitative reliability for the final version of both methods. 


\section{Chimney smoke}

Results from a chimney sample are given in the last column of Table 1 for comparison. This burning experiment differs by free air access without choking, and by inclusion of the glowing combustion phase following flaming. The proportion of coniferyl alcohol was lower than for the choked burning, whereas the proportions of the oxidised components coniferaldehyde and vanillin were higher. The proportions of the volatile compounds guaiacol and methylguaiacol also increased. These results are consistent with the differences in burning conditions and were confirmed in laboratory experiments with open burning and with glowing combustion.

A marked difference for the chimney sample was a higher proportion of 1,6anhydroglucose relative to the methoxyphenols. This anhydrosugar is a predominant thermal degradation product from cellulose (Kleen, Gellerstedt 1991). Coniferyl alcohol and other methoxyphenols are evidently released early in the burning succession, whereas 1,6anhydroglucose, from cellulose, is increasingly formed during the later stages including the glowing combustion. This also applies to other anhydrosugars as demonstrated by laboratory experiments. Paper made from delignified chemical pulp released almost no methoxyphenols on burning. Anhydrosugars and other compounds from degradation of polysaccharides then predominated.

\section{Release from lignin}

The complex network of lignin consists of substituted phenylpropane units bridged to each other by several differing characteristic linkages (Brunow et al. 1999). Phenolic $\beta$-ether linkages are particularly prominent. These linkages are broken by homolytic cleavage at elevated temperatures in aqueous solution as demonstrated for the lignin model guaiacylglycerol $\beta$-guaiacyl ether (Westermark et al. 1997). The reaction leads to continuing depolymerisation of lignin with formation of coniferyl alcohol. The reaction occurs already on production of thermomechanical and other high-yield pulps but increases rapidly with temperature. Analogous lignin degradation reactions on TMP newsprint burning may explain the formation of coniferyl alcohol as a primary component of the smoke.

In aqueous solution, coniferyl alcohol forms dimers and polymers (Westermark et al. 1997). The release of coniferyl alcohol into the gas phase on burning may decrease losses of coniferyl alcohol by such reactions. Dimers, also referred to as lignans, have been reported in fine smoke aerosols from wood burning (Simoneit et al. 1993). 


\section{Environmental and health aspects}

Because of its low volatility, coniferyl alcohol condenses rapidly on particles when leaving the hot combustion zone. Only the most volatile 2-methoxyphenols may appear significantly as gaseous air pollutants (Hawthorne et al. 1989). This means that coniferyl alcohol and other methoxyphenols should be excluded in inventories of emissions contributing to the formation of ground-level ozone.

Human exposure to small-size particles is presently discussed as a potentially serious health hazard. An important fact is that methoxyphenols have antioxidant properties (Barclay et al. 1997) which may decrease health hazards of particles in biomass smoke. Specific protective effects have been demonstrated for pure vanillin as the best known 2methoxyphenol (Tsuda et al. 1994).

Newsprint is often used to set wood on fire in residential fireplaces. This may cause significant indoor respiratory exposure to smoke particles with adsorbed coniferyl alcohol and coniferylaldehyde. The balance between protective and harmful effects of such exposure remains to be studied.

\section{Acknowledgement}

The authors thank Dr Knut Lundquist for information and discussions on lignin structure and reactions. 


\section{Literature}

Barclay, L.R.C., Xi, F. and Norris, J.Q. (1997): Antioxidant properties of phenolic lignin model compounds, Wood Chem. Technol. 17:1-2, 73-90.

Brunow, G., Lundquist, K. and Gellerstedt, G. (1999): Lignin, In: "Analytical Methods in Wood Chemistry; Pulping and Papermaking", Eds. E. Sjöström, R. Alén. Springer - Verlag, Berlin Heidelberg New York. pp 77-124.

Faix, O., Meier, D. and Fortmann, I. (1990): Thermal degradation products of wood - Gas chromatographic separation and mass spectrometric characterization of monomeric lignin derived products, Holz Roh - Werkstoff 48, 281-285.

Hawthorne S.B., Krieger M.S., Miller D.J. and Mathiason M.B. (1989): Collection and quantitation of methoxylated phenol tracers for atmosperic pollution from residential wood stoves, Environ. Sci. Technol. 23, 470-475.

Kjällstrand J., Ramnäs, O. and Petersson, G. (1998): Gas chromatographic and mass spectrometric analysis of 36 lignin-related methoxyphenols from uncontrolled combustion of wood, J. Chromatogr. A 824, 205-210.

Kjällstrand J., Ramnäs, O. and Petersson, G. (2000): Methoxyphenols from burning of Scandinavian forest plant materials, Chemosphere 41:5, 7-13 (scheduled).

Kleen M. and Gellerstedt, G. (1991): Characterization of chemical and mechanical pulps by pyrolysis - gas chromatography / mass spectrometry, J. Anal. Appl. Pyrolysis 19, 139-152.

Pouwels, A.D., Tom, A., Eijkel, G.B. and Boon, J.J. (1987): Characterisation of beech wood and its holocellulose and xylan fractions by pyrolysis - gas chromatography - mass spectrometry, J. Anal. Appl. Pyrolysis 11, 417 - 436.

Simoneit, B.R.T., Rogge, W.F, Mazurek, M.A., Standley, L.J., Hildemann L.M. and Cass, G.R. (1993): Lignin pyrolysis products, lignans, and resin acids as specific tracers of plant classes in emissions from biomass combustion, Environ. Sci. Technol. 27, 2533-2541.

Tsuda, H., Uehara, N., Iwahori, Y., Asamoto, M., Iigo, M., Nagao, M., Matsumoto, K., Ito, M., Hirono, I. (1994): Chemopreventive effects of $\beta$-carotene, $\alpha$-tocopherol and five naturally occurring antioxidants on initiation of hepatocarcinogenesis by 2-amino-3methylimidazo[4,5-f]quinoline in the rat, Jpn. J. Cancer Res. 85, 1214-1219.

Westermark U., Samuelsson, B. and Lundquist, K. (1997): Homolytic cleavage of the $\beta$ ether bond in phenolic $\beta-\mathrm{O}-4$ structures and its significance in high-yield pulping and lignin analysis, Nordic Pulp Paper Res. J. 12, 150-154. 